\title{
Role of Pharmacy on Alteration of Drug Cost and Drug-Related Problem Prevention for the National Health Insurance Geriatric Outpatient
}

\author{
Latifah $^{1}$, Rani Sauriasari ${ }^{1 *}$, Firzawati $^{2}$ \\ 'Faculty of Pharmacy, Universitas INDONESIA. \\ 2Bekasi Area Health Department, Ministry of Health, INDONESIA.
}

\begin{abstract}
Context: Indonesia has just taken a significant step in its efforts to roll out universal healthcare by established National Health Insurance (NHI) since 1 January 2014. Under NHI coverage, pharmacists' have an important role in preventing Drug Related Problems (DRPs) in geriatric patients through prescription review. Aims: The purpose of this study was to analyze the role of pharmacy in alteration drug costs through the prescription review to geriatric outpatient under $\mathrm{NHI}$ coverage and to determine the cost avoidance through a focus group discussion. Settings and Design: This study was held in general state hospital in Depok City and consist of two phase. The first phase was done with observational, retrospective, and pre-post study design. The second phase the discussion group were formed to determine cost avoidance. Methods and Material: The samples were taken from geriatric outpatient prescriptions from January to April 2016 and were designed to compare prescription costs before and after review by pharmacy staff. Statistical analysis used: Bivariate analysis was carried out to determine whether there is any difference between the cost of a prescription before and after pharmacists' prescription review. Results: The evaluation was performed on 599 prescriptions of geriatric outpatients. Prescription review resulted in cost savings of $3.78 \%$ from the total cost of pre-review prescriptions ( $R p 1,773,642)$. The prescription cost pre- and post-review was statistically significant by the Wilcoxon test $(p<0.05)$. The
\end{abstract}

cost increased to Rp. 97,392 after being given recommendations regarding the drug-related problem through discussion groups, but these increments can result in cost avoidance by Rp. 1,466,711.4. Conclusion: Optimization of pharmacists' roles can generate significant economic benefits (cost savings and cost avoidance).

Key words: Alteration of drug cost, Cost avoidance, Cost saving, Drug related problems, Geriatrics, Prescription review.

Key messages: The role of pharmacist in preventing DRPs in geriatric patients through prescription review in NHI era not only can improve medication in elderly but also have an economic impact such as saving and cost avoidance.

\section{Correspondence :}

Rani Sauriasari, Faculty of Pharmacy, Universitas Indonesia, 3rd Floor A Building RIK, Kampus UI, Depok, INDONESIA.

Phone numbers:+62 217270031

Facsimile numbers:+62 217864049

Email: rani@farmasi.ui.ac.id

DOI: 10.5530/jyp.2017.9.77

\section{INTRODUCTION}

The proper use of drugs can reduce the symptoms of the disease, prevent acute and chronic diseases and improve the health of patients. ${ }^{1}$ Nowadays the increased drug use is also impacted by the increasing misuse of drugs and increased occurrence of Adverse Drug Events (ADE). Improper use of drugs not only can lead to therapy failure, but it can also harm patients using these drugs. ${ }^{2}$ Geriatric patients are the biggest drug users compared with other age groups. Polypharmacy in geriatric patients may increase the prevalence of Drug Related Problems (DRP) ${ }^{3}$ and can be a major cause of patients admitted to hospital. ${ }^{4}$

The pharmacists have an important role in preventing of DRP in geriatric patients through clinical pharmacy services, including review the accuracy of each filled prescription. Studies demonstrated that pharmacist intervention can improve medication in elderly. ${ }^{5}$ The clinical pharmacy services also have an economic impact such as economic savings ${ }^{6}$ and cost avoidance. ${ }^{7}$ Economic savings refers to reductions in current spending, due to changes in the expenditure on a patient's treatment. ${ }^{8}$ Cost avoidance refers to an intervention that reduces or eliminates additional expenditure that otherwise may have been incurred in the absence of the intervention. ${ }^{9}$ Indonesia has just taken a significant step in its efforts to roll out universal healthcare by established National Health Insurance (NHI) since 1 January 2014. NHI is a health insurance program carried out by the Indonesian government. This insurance provides the protection of public health in meeting the needs of basic health of the Indonesian population. Implementation of NHI using the National Formulary as a list of drugs chosen to ensure the availability of quality drugs. Clinical pharmacy services have an important role in the NHI era. These services are required to optimize the activities of pharmaceutical care, which is expected to prevent the occurrence of adverse events, over and undertreatment. Pharmaceutical care in the NHI era can encourage quality improvement in patient-oriented services.

The general state hospital in Depok city is a government hospital that serves NHI participant and has conducted the prescription review as one of the clinical pharmacy services. The prescription reviews were limited to administrative aspects and compliance of the prescription to the national formulary. This activity can be done by a pharmacist or a pharmacist's assistant. The purpose of this study was to analyze the role of pharmacists and pharmacist's assistants in altering drug costs through the prescription review of geriatric outpatient under NHI. Furthermore, the pharmacist will determine the cost avoidance through discussion groups. 


\section{Subjects and Methods}

The samples in our study were taken from geriatric outpatient prescription in January until April 2016 in a general state hospital in Depok city. All prescriptions from geriatric outpatients (aged 60 years or more), who registered as NHI participants in the period of the study, which had been review by pharmacy staff (a pharmacist or a pharmacist's assistant) were included. Prescriptions were excluded if illegible, had no diagnosis, had no details of prescription medication costs and when the patient did not get the medicine because of stock out. Sampling was done by purposive sampling.

This study was consisted of two phase. The first phase was done with observational, retrospective, and pre-post study design to analyze the role of pharmacists and pharmacist's assistants in altering drug costs through the prescription review of geriatric outpatient under NHI. The second phase the discussion group were formed to assess the role of pharmacist in DRP prevention and determine cost avoidance. The discussion group consisted of 4 pharmacists who worked in this hospital. The purposes of this discussion group are to conduct a study on the clinical aspects such as prescription medication duplication, contraindications, drug interactions, indication the accuracy, dosage and timing of drug use. The pharmacists in this group give the recommendations on the DRP. Each pharmacist assesses 20 recipes drawn at random. The DRPs were obtained on this discussion group were further classified by PCNE V6.2.

\section{Calculation of alteration in drug costs}

Calculation of drug cost alteration was determined by calculating the difference in the cost of prescription after and before the review. Alteration of drug costs can generate cost savings when the cost of prescription after the review is smaller than the cost of the previous one. Formula calculation is carried out as follow:
Alteration of drug costs $=$ Cost of prescription after prescription review Cost of prescription before prescription review

The sample of calculation of drug cost alteration was shown on Table 1. Using the formula above, the alteration of drug cost in table 1 are:

Alteration of drug costs $=6,081-7,418$

$$
=(1,337)
$$

The bivariate analysis performed to determine whether there is any difference between the cost of a prescription before and after review. Bivariate analysis was conducted using paired $t$-test if the data normally distributed or using Wilcoxon method if it is not normal.

\section{Calculation of cost avoidance}

The calculation of cost avoidance can be done using a method that has been used by Nesbit, as follows ${ }^{8}$

Cost Avoidance $=$ probability of occurrence $A D E x$ costs of an $A D E$ The cost of an ADE events based on the previous study was USD 53. ${ }^{10}$ When converted into rupiah, the cost incidence of ADE is Rp 698,434. The value of the probability of occurrence ADE was shown on Table 2.

\section{RESULTS}

A total of 682 prescriptions were reviewed by pharmacist and assistant's pharmacist. 83 prescriptions were excluded because the prescriptions were illegible (16 prescriptions), there were no details of the cost of prescription medication (12 prescriptions), there were no diagnosis (36 prescriptions), and the patient did not get the medicine because of stock out (19 recipes). Total prescriptions that were analyzed in this study was 599 recipes. The characteristics of patients were described in Table 3.

Table 1: The sample of calculation of drug cost alteration

\begin{tabular}{|c|c|c|c|c|c|c|c|}
\hline \multicolumn{4}{|c|}{ Before Prescription Review } & \multicolumn{4}{|c|}{ After Prescription Review } \\
\hline Drug name & Qty & Price (Rp) & $\begin{array}{c}\text { Total Cost of } \\
\text { Prescription (Rp) }\end{array}$ & Drug Name & Qty & Price (Rp) & $\begin{array}{c}\text { Total Cost of } \\
\text { Prescriptions (Rp) }\end{array}$ \\
\hline Furosemide $40 \mathrm{mg}$ & 7 & 97 & 679 & Furosemide $40 \mathrm{mg}$ & 7 & 97 & 679 \\
\hline Spironolactone $25 \mathrm{mg}$ & 8 & 362 & 2,896 & Spironolactone $100 \mathrm{mg}$ & 2 & 1,035 & 2,070 \\
\hline Captopril $12.5 \mathrm{mg}$ & 7 & 71 & 497 & Captopril $12.5 \mathrm{mg}$ & 7 & 71 & 497 \\
\hline Aspilet $80 \mathrm{mg}$ & 7 & 367 & 2,569 & $\begin{array}{c}\text { Acetylsalicylic acid } 80 \\
\text { mg (Miniaspi) }\end{array}$ & 7 & 294 & 2,058 \\
\hline Digoxin $0.25 \mathrm{mg}$ & 7 & 111 & 777 & Digoxin $0.25 \mathrm{mg}$ & 7 & 111 & 777 \\
\hline \multicolumn{3}{|c|}{ Total } & 7,418 & \multicolumn{3}{|c|}{ Total } & 6,081 \\
\hline
\end{tabular}

Table 2 : Probability of occurrence of ADE to calculate cost avoidance

\begin{tabular}{ccl}
$\begin{array}{c}\text { The probability of } \\
\text { occurrence of ADE }\end{array}$ & $\begin{array}{c}\text { Probability } \\
\text { score }\end{array}$ & Example \\
\hline $\begin{array}{c}\text { Not harmful } \\
\text { Very low }\end{array}$ & 0.00 & $\begin{array}{l}\text { Pharmacists recommend changes esomeprazole into omeprazole therapy due to cost considerations. } \\
\text { Clarification to the doctor due to incomplete information, such as clarifying the strength of the preparation, rules of use, } \\
\text { dosage forms, etc. }\end{array}$ \\
Low & 0.01 & $\begin{array}{l}\text { Interventions against drug administration at a dose of } 2-4 \mathrm{x} \text { the normal dose, interventions against the drug dose is not } \\
\text { sufficient to produce a therapeutic effect, the intervention of the time / improper use of drugs that could potentially } \\
\text { lead to therapeutic failure or the occurrence of toxic effects, interventions against duplication therapeutic potential } \\
\text { occurrence of toxic effects } \\
\text { Interventions against drug administration with a dose of } 4-10 \mathrm{x} \text { normal, intervention in dose adjustment in patients with } \\
\text { renal failure } \\
\text { Intervention in the administration of drugs with } 10 \mathrm{x} \text { the normal dose, intervention on the use of drugs with a narrow } \\
\text { therapeutic index, intervention on the use of drugs that cause reactions anaphylaxis }\end{array}$ \\
Hoderate & 0.40 &
\end{tabular}


Table 3 : Patients Characteristics

\begin{tabular}{ll}
\hline \multicolumn{1}{c}{ Characteristics } & \multicolumn{1}{c}{$\begin{array}{c}\text { Amount } \\
\mathbf{n}=599(\%)\end{array}$} \\
\hline Sex & $326(54.4)$ \\
Man & $273(45.6)$ \\
female & \\
Age (years) & $219(36.6)$ \\
$60-64$ & $176(29.4)$ \\
$65-69$ & $135(22.5)$ \\
$70-74$ & $69(11.5)$ \\
$>74$ & \\
Diagnosis & $74(12.35)$ \\
Diabetes mellitus & $43(7.18)$ \\
Pseudophakic & $42(7.01)$ \\
Stroke & $34(5.68)$ \\
Congestive heart failure & $30(5.01)$ \\
Cataract & $376(62.77)$ \\
Etc &
\end{tabular}

\section{Phase I}

In the first phase, total alteration in drug costs in this study was Rp. $1,773,642$ which corresponded to $3.78 \%$ from the total cost of prescription, before the prescription review. Table 4 show the 10 largest-alterations of drug cost, based on the diagnosis.

\section{Phase II}

In the second phase, the prescription review by the pharmacist in the discussion group obtained 16 cases DRP. The details were shown in table 5.

Based on the recommendations given by the pharmacist in the group discussions, only a recommendation to replace (8 recommendation) and to discontinue the use of a medicine (1recommendation) can produce the alteration in the drug cost. Prescription costs after a recommendation was given by the pharmacist were greater than the previous one. The addition of drug costs was Rp. 97,392 (Table 6). Total cost avoidance gen- erated after a recommendation by a pharmacist in the discussion group is Rp. 1,466,711.4 (Table 7).

\section{DISCUSSION}

Our results in the first phase show that prescription costs after the prescription review were lower comparatively to the initial values. This shows that pharmacists and pharmacist assistants have an important role in economic impact, especially in cost saving. The value of cost savings generated in this study is not too large, amounting to $3.78 \%$ of the total cost of a prescription before the prescription review. This can be due to the fact that prescrition review only was done on the administrative aspects. Intervention by pharmacists and assistant pharmacists in this study consisted solely on drug substitution due to drug shortages or stock out, or when prescriptions were not in accordance with the national formulary. In a recent study from the value of cost savings derived from the active role of the pharmacist in pharmaceutical care activities tend to reduced overall drug cost, cost saving and cost avoidance. ${ }^{10}$ Based on the pharmacist's recommendations in group discussions in the second phase, the cost of prescription after the recommendation was greater than the cost of the previous one. The cost increased to Rp. 97,392. This is because the drugs previously prescribed drugs that have replaced with more expensive prices. This case occurred on the replacement of fluoxetine with sertraline, amitriptyline with maprotiline, and replacement of fluoxetine with quetiapine. Selection of these drugs is expected to be safer for geriatric patients, so as to increase the effectiveness of treatment. Selection of sertraline is considered more appropriate for geriatric patients compared to fluoxetine. Administering drugs Selective Serotonin Reuptake Inhibitors (SSRIs) such as fluoxetine was not the first choice in geriatric patients. Fluoxetine has a long half-life, so it can prolong the drug's side effects. Fluoxetine also has a high risk to interact with other drugs. A safer option for the SSRI class of drugs in geriatric patients is citalopram, escitalopram or sertraline. ${ }^{11}$ Tricyclic antidepressants (TCAs) such as amitriptyline in geriatric patients was not the first choice for the consideration of side effects such as postural hypotension, and anticholinergic effects. ${ }^{11}$ Compared to amitriptyline, maprotiline has lower anticholinergic effects and weaker affinity for the receptor $\alpha_{1}{ }^{12}$ Total cost avoidance generated after a recommendation by a pharmacist in the discussion group is Rp. 1,466,711.4. This suggests although the change in drug costs become greater after recommendation by the pharmacist, but these recommendations can prevent ADE costs significantly. Although the prescription review in general state hospital in Depok city

Table 4 : The 10 largest drug cost alteration by diagnosis

\begin{tabular}{|c|c|c|c|c|}
\hline \multirow[b]{2}{*}{ No. } & \multirow[b]{2}{*}{ Diagnosis } & \multicolumn{2}{|c|}{ Prescription Cost (Rp) } & \multirow{2}{*}{$\begin{array}{l}\text { Alteration in } \\
\text { Drug Costs (Rp) }\end{array}$} \\
\hline & & $\begin{array}{c}\text { Before Prescription } \\
\text { Review }\end{array}$ & $\begin{array}{c}\text { After Prescription } \\
\text { Review }\end{array}$ & \\
\hline 1 & Stroke & $3,084,575$ & $2,723,108$ & $(361,467)$ \\
\hline 2 & Cataract & $1,981,195$ & $1,806,627$ & $(174,568)$ \\
\hline 3 & Lower back pain & $1,194,524$ & $1,021,826$ & $(172,698)$ \\
\hline 4 & Diabetes mellitus & $10,496,901$ & $10,325,786$ & $(171,115)$ \\
\hline 5 & Congestive heart failure & $2,064,222$ & $1,925,140$ & $(139,082)$ \\
\hline 6 & Polyneuropathy & $1,215,897$ & $1,086,474$ & $(129,423)$ \\
\hline 7 & Dyspepsia & 612,802 & 484,458 & $(128,344)$ \\
\hline 8 & Chronic Obstructive Pulmonary Disease (COPD) & 124,575 & 12,836 & $(111,739)$ \\
\hline 9 & Osteoarthritis (OA Genu) & 331,736 & 238,479 & $(93,257)$ \\
\hline 10 & Bronchitis & 234,525 & 146,068 & $(88,457)$ \\
\hline \multirow[t]{2}{*}{11} & Etc & $25,532,406$ & $25,328,914$ & $(203,492)$ \\
\hline & Total & $46,873,358$ & $45,099,716$ & $(1,773,642)$ \\
\hline
\end{tabular}


Table 5 : DRP Classification based on PCNE V6.2

\begin{tabular}{|c|c|}
\hline Classification & Frequency \\
\hline \multicolumn{2}{|l|}{ Problem } \\
\hline Undesirable events (non-allergic) (P2.1) & 16 \\
\hline \multicolumn{2}{|l|}{ Cause } \\
\hline Inappropriate Drugs Combination (C1.3) & 11 \\
\hline - The use of acetylsalicylic acid (anti-platelet) with meloxicam & 7 \\
\hline - The use of quetiapine with risperidone & 1 \\
\hline - The use amitriptyline with fluoxetine & 1 \\
\hline - The use of fluoxetine with clozapine & 1 \\
\hline - The use of fluoxetine with risperidone & 1 \\
\hline Improper duplication (C1.4) & 5 \\
\hline - The use of two Non-steroidal Anti-Inflammation Drug (NSAID) (mefenamic acid and sodium diclofenac) & 5 \\
\hline \multicolumn{2}{|l|}{ Intervention } \\
\hline Inform the doctor (I1.1) & 9 \\
\hline Provide drug counseling in patients (I2.1) & 7 \\
\hline Changing medications (I3.1) & 8 \\
\hline Stopping treatment (I3.5) & 1 \\
\hline
\end{tabular}

Table 6 : Prescription drug cost alteration, based on the recommendation of pharmacists

\begin{tabular}{cccc}
\hline & \multicolumn{3}{c}{ Prescription Cost (Rp) } \\
\cline { 2 - 4 } No. & $\begin{array}{c}\text { Prior Prescription Review and } \\
\text { Recommendations Pharmacists }\end{array}$ & $\begin{array}{c}\text { After Prescription Review and } \\
\text { Recommendations Pharmacists }\end{array}$ & $\begin{array}{c}\text { Alteration in Drug } \\
\text { Costs (Rp) }\end{array}$ \\
\hline 1 & 411,270 & 409,950 & $(1,320)$ \\
2 & 85,482 & 79,034 & $(6,448)$ \\
3 & 119,226 & 134,823 & 15,597 \\
4 & 73,200 & 40,510 & $(32,690)$ \\
5 & 77,320 & 45,938 & $(31,382)$ \\
6 & 107,345 & 170,492 & 63,147 \\
7 & 346,675 & 338,562 & $(8,113)$ \\
8 & 87,86 & 84,119 & 75,333 \\
9 & 48,573 & 71,841 & 23,268 \\
Total & $\mathbf{1 , 2 7 7 , 8 7 7}$ & $\mathbf{1 , 3 7 5 , 2 6 9}$ & $\mathbf{9 7 , 3 9 2}$ \\
\hline
\end{tabular}

Table 7 : Cost avoidance generated by pharmacist intervention

\begin{tabular}{cccc} 
Type of Recommendation & $\begin{array}{c}\text { Frequency } \\
\text { Recommendation }\end{array}$ & Probability score & $\begin{array}{c}\text { Cost Avoidance (Rp) } \\
\text { (The probability of ADE x Rp. 698. 434 x } \\
\text { Frequency Recommendation) }\end{array}$ \\
\hline $\begin{array}{c}\text { Drug Interaction } \\
\text { Duplicate use of NSAIDs }\end{array}$ & 4 & 0.4 & $1,117,494.4$ \\
\multicolumn{2}{c}{ Total Cost Avoidance } & 0.1 & 349,217 \\
\hline
\end{tabular}

just limited on the review of administrative aspect, but it can lead to reduced cost prescription and result in cost saving. The optimization in pharmacist role is very important to prevent DRP in geriatric outpatient and also can lead cost avoidance.

\section{CONCLUSION}

In conclusion, optimization of pharmacists' roles can generate significant economic benefits (cost savings and cost avoidance) in NHI era.

\section{ACKNOWLEDGEMENT}

The authors would like to thank to general state hospital in Depok City, especially for Pharmacy Installation for helping to supply the data in this study.

This study was financially supported by PITTA Grant, Universitas Indonesia (No. 1825/UN2.R12/HKP.05.00/2016) and we are thanks to DRPM (Directorate of Research and Community Engagement) Universitas Indonesia for their assistance. 


\section{CONFLICT OF INTEREST}

Authors do not have any conflict of interest.

\section{REFERENCES}

1. Viswanathan M, Kahwati LC, Golin CE, Blalock SJ, Coker-schwimmer E, Posey R, et al. Medication therapy management interventions in outpatient settings: a systematic review and meta-analysis. JAMA internal medicine. 2015;175(1):76-87. https://doi.org/10.1001/jamainternmed.2014.5841; PMid:25401788.

2. Kohn LT, Corrigan JM, Donaldson MS. To Err Is Human: Building a Safer Health System. Washington D.C: National Academy Press; 1999.

3. RahmawatiY, Sunarti S. Drug-Related Problem in Hospitalized Geriatric Patients at Saiful Anwar Hospital Malang. J Kedokt Brawijaya. 2011;28:140-4.

4. Somers A, Robays H, Vander Stichele R, Van Maele GE, Bogaert M, et al. Contribution of drug related problems to hospital admission in the elderly. The journal of nutrition, health \& aging. 2010;14(6):477-82. https://doi.org/10.1007/s12603009-0237-0.

5. Reilly $T$, Barile D, Reuben S. Role of the pharmacist on a general medicine acute care for the elderly unit. The American journal of geriatric pharmacotherapy. 2012;10(2):95-100. https://doi.org/10.1016/j.amjopharm.2012.02.002; PMid:22387106.

6. Patel R, Butler K, Garrett D, Badger N, Cheoun D, Hallman L. The impact of a pharmacist's participation on hospitalists' rounds. Hospital Pharmacy.
2010;45(2):129-34. https://doi.org/10.1310/hpj4502-129.

7. Gallagher J, Byrne S, Woods N, Lynch D, McCarthy S. Cost-outcome description of clinical pharmacist interventions in a university teaching hospital. BMC health services research. 2014;14(1):177. https://doi.org/10.1186/1472-6963-14177; PMid:24742158 PMCid:PMC4020601.

8. Nesbit TW, Shermock KM, Bobek MB, Capozzi DL, Flores PA, Leonard MC, Long JK, Militello MA, White DA, Barone LD, Goldman MP. Implementation and pharmacoeconomic analysis of a clinical staff pharmacist practice model. American journal of health-system pharmacy. 2001;58(9):784-90.PMid:11351918.

9. Campbell AR, Nelson LA, Elliott E, Hieber R, Sommi RW. Analysis of cost avoidance from pharmacy students' clinical interventions at a psychiatric hospital. American journal of pharmaceutical education. 2011;75(1):8. https:// doi.org/10.5688/ajpe7518; PMid:21451760 PMCid:PMC3049667.

10. Saokaew S, Maphanta S, Thangsomboon P. Impact of pharmacist's interventions on cost of drug therapy in intensive care unit. Pharmacy Practice (Internet) 2009;7(2):81-7. https://doi.org/10.4321/S1886-36552009000200003.

11. Wiese BS. Geriatric depression: The use of antidepressants in the elderly. BCMJ. 2011;53(7):341-7.

12. Baxter K. Stockley's drug interactions. Preston CL, editor. London: Pharmaceutical Press; 2010

Article History: Submission Date : 16-02-2017; Revised Date : 25-03-2017; Acceptance Date : 04-05-2017.

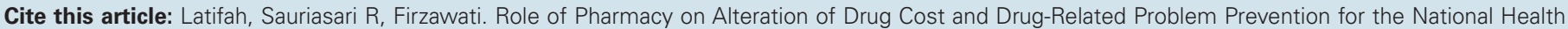
Insurance Geriatric Outpatient. J Young Pharm. 2017;9(3):386-90. 